\title{
Altman Z-Score Vs Zmijewski X-Score Dalam Memprediksi Kebangkrutan Perusahaan (Studi Kasus PT Tiga Pilar Sejahtera Food, Tbk (AISA) Tahun 2015-2017
}

\author{
Fanita Dahni \\ Magister Manajemen Universitas Katolik Parahyangan \\ Email: Fanitase@gmail.com
}

\begin{abstract}
Many kinds of methods for predicting bankruptcy have their respective characteristics and each method have different characteristics. The results of the calculation of each method can give the same or even different results. In this study intended to predict whether the PT Tiga Pilar Sejahtera Food, Tbk (AISA) the results of the Altman Z-Scores and Zmijewski calculations have the same results, both of which can predict the company bankrupt, not bankrupt, or both models produce different results. In conducting this research, the author uses descriptive study methods and case studies. The data used are secondary data obtained from the company's official website. The research proves that: (1) Altman Z-Score calculation predicts that AISA indicates bankruptcy in the 2015-2017 periods; (2) Zmijewski X-Score calculation predicts that AISA is in safe condition; (3) There are differences in the calculation results between Altman ZScore and Zmijewski X-Score; (4) Differences can be triggered by differences in the ratio components used in the calculation of each method. This research is only a description of the company's condition which is not $100 \%$ correct. The results of the calculation methods are used as an evaluation in the future so that the company can improve its performance. This research can also be used as an illustration to make investment decisions for investors.
\end{abstract}

\begin{abstract}
Abstraksi: Metode untuk memprediksi kebangkrutan yang beragam mempunyai karakteristiknya masingmasing dan antar metode mempunyai karakteristik yang berbeda-beda. Hasil perhitungan masing-masing metode pun bisa memberikan hasil yang sama atau bahkan berbeda. Dalam penelitian ini dimaksudkan untuk membandingkan metode prediksi kebangkrutan Altman Z-Scores dan Zmijewski X-Scores terhadap PT Tiga Pilar Sejahtera Food, Tbk (AISA) periode tahun 2015-2017, apakah hasil perhitungan Altman Z-Scores dan Zmijewski memiliki arah hasil yang sama atau kedua model tersebut menghasilkan arah hasil yang berbeda. Dalam melakukan penelitian ini, penulis menggunakan metode studi deskriptif dan studi kasus. Data yang digunakan adalah data sekunder yang diperoleh dari website resmi perusahaan. Hasil penelitian membuktikan bahwa: (1) Perhitungan Altman Z-Score memprediksi bahwa AISA terindikasi kebangkrutan pada periode 2015-2017;(2) Perhitungan Zmijewski X-Score memprediksi bahwa AISA dalam kondisi yang sehat;(3) Adanya perbedaan hasil perhitungan antara Altman Z-Score dan Zmijewski X-Score; (4) Perbedaan dapat dipicu oleh adanya perbedaan komponen-komponen rasio yang digunakan dalam perhitungan masing-masing metode. Penelitian ini hanya sebagai gambaran keadaan perusahaan yang tidak 100\% benar. Hasil perhitungan metode-metode digunakan sebagai evaluasi kedepannya agar perusahaan dapat memperbaiki kinerjanya. Penelitian ini juga bisa dijadikan gambaran untuk mengambil keputusan investasi bagi para investor.
\end{abstract}

Keywords: Bankcruptcy; Altman Z-Score; Zmijewski X-Score; and Financial Ratio

\section{Pendahuluan}

Sektor makanan dan minuman Indonesia menunjukkan peningkatan yang mampu menembus pertumbuhan ekonomi nasional di triwulan I-2019 yang tumbuh sebesar 5,07 persen. Sektor makanan dan minuman mampu tumbuh sebesar 6,77 persen. (neraca.co.id, 2019). Peningkatan pertumbuhan sebelumnya sudah ditunjukkan pada tahun 2015-2017, seperti yang terlihat pada Gambar 1.

Bertolak belakang dengan keadaan pertumbuhan industri makanan dan minuman yang cukup stabil bahkan cenderung mengalami peningkatan, salah satu perusahaan makananan yang sudah ada sejak tahun 1992 sedang dilanda isu kebangkrutan sejak akhir tahun 2017 lalu, yaitu PT Tiga Pilar Sejahtera Food, Tbk. (TPS). Reputasi 
TPS hancur lantaran anak usaha TPS, PT Indo Beras Unggul terlilit skandal kasus hukum kecurangan penjualan beras premium pada 2017. Sehingga pada akhir tahun 2017, Tiga Pilar mulai memangkas semua bisnis beras nya dan sejak saat itu Tiga Pilar Sejahtera Food hanya focus untuk menjalankan bisnis produksi makanan ringannya (businessinsight.kontan.co.id, 2018).
Implikasi Negatif”. Obligor dengan peringkat ini rentan, dan tergantung pada kondisi bisnis dan keuangan yang menguntungkan untuk memenuhi komitmen keuangannya. Peringkat ini mencerminkan likuiditas dan perlindungan arus kas perusahaan yang lemah, struktur permodalan Perusahaan yang agresif, eksposur terhadap fluktuasi biaya bahan baku, dan persaingan yang ketat di industri (PEFINDO, 2018).

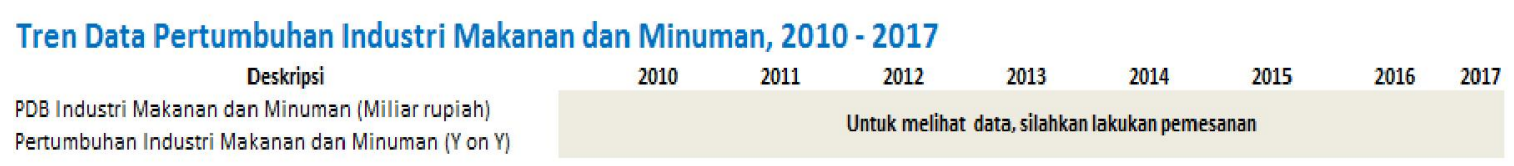

Sumber: Dataindustri Research, diolah dari Badan Pusat Statistik (BPS) dan Bank Indonesia (BI)

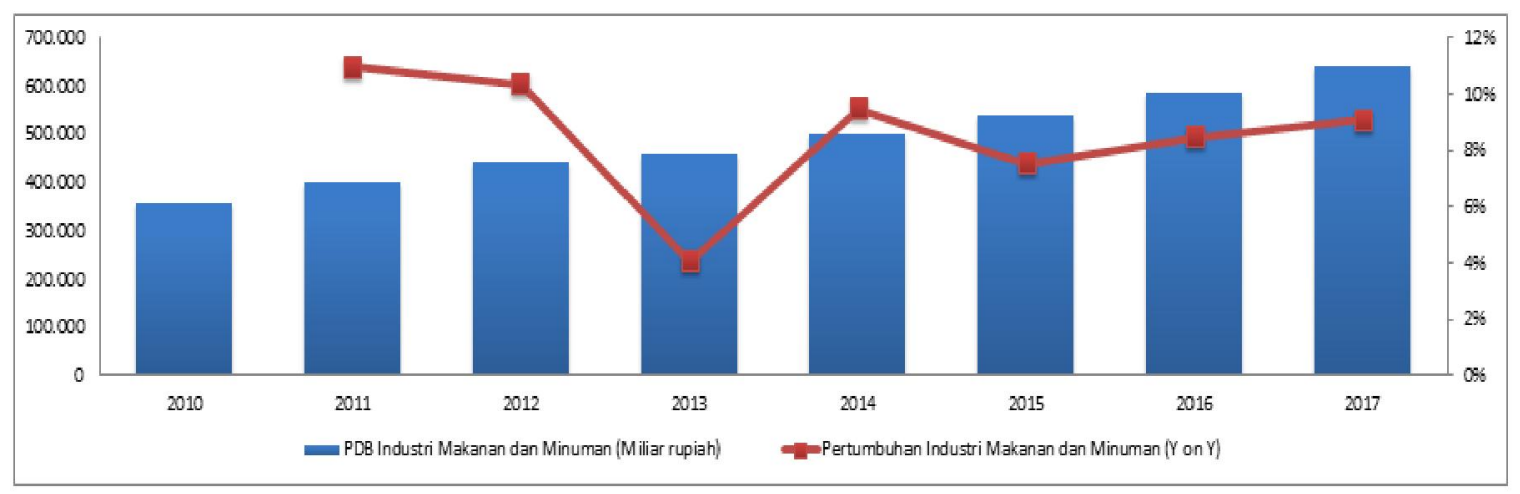

Gambar 1. Data Pertumbuhan Industri Makanan dan Minuman 2010-2017

Sumber: Dataindustri Research (dataindustri.com, 2017)

Pasca menghentikan operasional bisnis beras, para karyawan Tiga Pilar yang kena imbasnya. Sebanyak kurang lebih 1.700 karyawan diputus kontak kerjanya (ekonomi.kompas.com, Hentikan Bisnis Beras, PT Tiga Pilar PHK 1700 Karyawan, 2017). Tidak hanya berhenti disana, pada 2017 lalu, harga saham masih mentereng di posisi Rp 2.200 per saham. Sampai pada Juni tahun 2018, saham TPSF terus anjlok mencapai titik Rp 280 per saham. (tirto.id, 2018).

Selain sirnanya bisnis beras, TPS sempat mengalami kasus Penundaan Kewajiban Pembayaran Utang (PKPU) pada tahun 2018. Kasus tersebut kemudian banyak diartikan sebagai indikasi pailit atau kebangkrutan bagi AISA.

PEFINDO menempatkan peringkat “idCCC" PT Tiga Pilar Sejahtera Food, Tbk (AISA) pada "Credit Watch dengan
Dilihat dari sisi laporan keuangan Laba/Rugi PT Tiga Pilar Sejahtera Food, Tbk (TPSF). Tahun 2015-2017, pendapatan perusahaan mengalami fluktuasi ekstrem. Tahun 2015 ke 2016, perusahaan sempat mengalami peningkatan pendapatan. Namun, perusahaan juga mengalami kerugian pada tahun 2017 mencapai $100 \%$ dari keuntungannya pada tahun 2016.

Tabel 1. Laba/Rugi TPSF tahun 2015-

\begin{tabular}{llll}
\multicolumn{4}{c}{2017} \\
\hline & $\mathbf{2 0 1 5}$ & $\mathbf{2 0 1 6}$ & $\mathbf{2 0 1 7}$ \\
\hline $\begin{array}{l}\text { Laba/Rugi } \\
\text { (dalam }\end{array}$ & 379,032 & 706,681 & $(859,521)$ \\
$\begin{array}{l}\text { jutaan } \\
\text { rupiah) }\end{array}$ & & & \\
\hline
\end{tabular}

Sumber: Laporan Keuangan AISA (2019)

Financial distress dapat dialami perusahaan apabila kewajiban yang dimiliki perusahaan lebih besar dari pada kekayaan (aset), ukuran dan laba perusahaan (Lin, $\mathrm{Zu}$ - 
Hsu, \& Gibbs, 2008). Berdasarkan data laporan laba/rugi perusahaan dan kasus-kasus yang sedang menjerat perusahaan, perusahaan TPSF sudah diindikasi terjangkit financial distress. Dari keadaan tersebut, perusahaan harus mulai waspada dan mencari solusi atas permasalahan dan kesulitan keuangan yang dialaminya. Apabila solusi bisa cepat didapatkan maka akan menjadi tindakan preventif untuk mengantisipasi keadaan yang mungkin saja bisa memburuk di masa akan datang. Sebelum kebangkrutan terjadi, kesulitan keuangan menjadi tanda yang cukup mencerminkan indikasi kebangkrutan (Rahayu \& Putri, 2016).

Sehingga maksud penelitian ini adalah untuk membuktikan apakah ada indikasi kebangkrutan yang akan dialami oleh PT Tiga Pilar Sejahtera Food, Tbk (TPSF). Mengingat bahwa sudah banyak kasus kebangkrutan yang dialami perusahaanperusahaan di Indonesia yang akarnya pun tidak disadari sedini mungkin (Adriana, 2012). "Bankruptcy is business failure that occurs when the started value of a firm's liabilities exceeds the fair value if its assets." (Gitman \& Zutter, 2012)

Prediksi kebangkrutan perusahaan dapat dilakukan dengan menggunakan Model Altman Z-Scores dan Model Zmijewski. Rasio-rasio dalam perhitungan Zmijewski memfokuskan pada seberapa mampu aset yang dimiliki perusahaan untuk menutupi hutang-hutangnya (Permana, Ahmar, \& Djaddang, 2017). Model Zmijewski (1984) merupakan model yang dikembangkan berdasarkan hasil uji coba dan analisis selama kurang lebih 20 tahun (Wulandary \& Nur, 2014).

Model Altman (1984) menemukan bahwa perusahaan dengan profitabilitas serta solvabilitas yang rendah sangat berpotensi mengalami kebangkrutan. Ia juga mencoba mengembangkan model prediksi kebangkrutan dengan menggunakan 22 rasio keuangan yang diklasifikasikan ke dalam lima kategori rasio yaitu likuiditas, profitabilitas, leverage, rasio uji pasar, dan aktivitas (Arum \& Handayani, 2018).
Berdasarkan penelitian yang dilakukan oleh Hariyani \& Sujianto (2017) disimpulkan bahwa terdapat perbedaan ketiga model prediksi kebangkrutan yaitu model Altman, Springate, dan Zmijewski terhadap Bank Syariah di Indonesia. Penelitian lain yang dilakukan oleh Primasari (2017) terhadap perusahaan-perusahaan dalam industri barang-barang konsumsi di BEI pada periode 2012-2015 membuktikan bahwa adanya perbedaan hasil analisis prediksi kebangkrutan antara 4 model (model altman, model grover, model springate, dan model zmijewski) dalam memberikan signaling kondisi financial distress. Perbedaan hasil tersebut dikarenakan adanya perbedaan dalam menggunakan perhitungan rasio-rasio pada masing-msaing model tersebut.

Penelitian ini dimaksudkan untuk membandingkan metode prediksi kebangkrutan Altman Z-Scores dan Zmijewski $X$-Scores terhadap PT Tiga Pilar Sejahtera Food, Tbk (AISA) periode tahun 2015-2017, apakah hasil perhitungan Altman Z-Scores dan Zmijewski memiliki arah hasil yang sama atau kedua model tersebut menghasilkan arah hasil yang berbeda.

Seluruh model yang digunakan untuk memprediksi kebangkrutan sebenarnya hanya sebagai signaling factor untuk kondisi keuangan perusahaan dalam situasi dan periode tertentu. Namun, model prediksi kebangkrutan juga bisa memberikan dampak positif dalam membuat kebijakan mengenai keuangan perusahaan untuk memprediksikan keadaan dan kebutuhan operasional atau likuiditasnya. Hasil prediksi model-model kebangkrutan dipergunakan sebagai indikator atau tolak ukur bagi para shareholders maupun stakeholders dalam upaya evaluasi dan memperbaiki kinerja perusahaan dimasa akan datang. Investor tentu memerlukan juga informasi perusahaan yang ingin dijadikan ladang investasi agar investor lebih berhatihati dalam mengambil keputusan.

\section{Kajian Teori}

Altman Z-Score 
Model yang dinamakan Z-score oleh Edward I.Altman yang dikembangkannya pada tahun 1968 merupakan suatu model linear dengan komponen perhitungannya didasarkan pada rasio-rasio keuangan yang diberikan skor masing-masing yang sesuai untuk memprediksi kebangkrutan perusahaan. Altman mengembangkan modelnya dengan menggunakan analisis multidiskriminan. Untuk menguji modelnya tersebut, Ia menggunakan 66 sampel dengan kategori 33 perusahaan bangkrut dan 33 perusahaan tidak bangkrut (Fanny \& Saputra, 2005). Rasio-rasio yang terpilih ditunjukkan dalam persamaan berikut (Altman, 1968):

$Z(0)=1,2 X 1+1,4 X 2+3,3 X 3+0,6 X 4+0,999 \times 5$

Keterangan:

$$
\begin{aligned}
& \text { X1 : Modal Kerja / Total Aset } \\
& \text { X2 : Laba Ditahan / Total Aset } \\
& \text { X3 : EBIT / Total Aset } \\
& \text { X4 : Nilai Pasar Saham / Total Utang } \\
& \text { X5 : Penjualan / Total Aset }
\end{aligned}
$$

Skor $\mathrm{Z}$ yang akan diperoleh merupakan gabungan dari 5 (lima) komponen rasio dan koefisien yang berbeda. Nilai $\mathrm{Z}$ adalah indeks keseluruhan fungsi multiple discriminant analysis (MDA). Angka-angka cut off nilai $\mathrm{Z}$ dibagi ke dalam tiga kategori, yaitu sebagaimana ditunjukkan pada Tabel 2 .

Tabel 2. Intrepretasi Model Altman Z-

\begin{tabular}{ll}
\multicolumn{2}{c}{ Score Z(0) } \\
\hline Skor Z & Indikasi \\
\hline$<1,81$ & $\begin{array}{l}\text { Kemungkinan perusahaan dekat } \\
\text { dengan kebangkrutan (Distress } \\
\text { Zone) }\end{array}$ \\
\hline $1,81 \leq \mathrm{Z}$ & $\begin{array}{l}\text { Daerah ragu-ragu artinya ada } \\
\text { kemungkinan }\end{array}$ \\
& $\begin{array}{l}\text { mengklasifikasikan perusahaam } \\
\text { atau perusahaan bisa bangkrut } \\
\text { dan bisa tidak bangkrut (Grey }\end{array}$ \\
& Zone) \\
\hline$>2.99$ & $\begin{array}{l}\text { Perusahaan yang baik/tidak } \\
\text { bangkrut (Safe Zone) }\end{array}$ \\
\hline
\end{tabular}

Sumber: Sundjaja, Barlian, \& Sundjaja (2013)

\section{Zmijewski X-Score}

Zmijewski (1984) adalah nama penemu model prediksi kebangkrutan yang kemudian model nya dikenal dengan namanya sendiri. Zmijewski menggunakan analisa rasio yang mengukur beberapa kinerja seperti, leverage/hutang, profitabilitas, serta likuiditas suatu perusahaan. Model yang berhasil dikembangkan yaitu (Zmijewski, 1984):

$$
X-\text { Score }=-4.3-4.5 \mathrm{X} 1+5.7 \mathrm{X} 2-0.004 \mathrm{X} 3
$$

Keterangan:

$\mathrm{X} 1=$ return on asset

$\mathrm{X} 2=$ debt ratio

$\mathrm{X} 3$ = current ratio

Zmijewski (1984) menyatakan bahwa perusahaan dianggap distress atau akan bangkrut jika probabilitasnya lebih besar dari 0. Maka, nilai cut-off yang berlaku dalam model ini adalah 0. Apabila hasil $X$-score bernilai negatif atau kurang dari 0 ( $X$-Score $<$ 0 ), maka perusahaan tersebut dikatakan dalam kondisi yang sehat atau tidak bangkrut. Sebaliknya apabila hasil $X$-score bernilai positif atau lebih dari sama dengan 0 $(X$-Score $\geq 0)$ maka perusahaan tersebut dapat digolongkan dalam kondisi yang tidak sehat atau cenderung mengarah ke kebangkrutan.

\section{Metode}

\section{Jenis Penelitian}

Dalam melakukan penelitian ini, penulis menggunakan metode studi deskriptif. "Descriptive studies are often designed to collect data that describe the characteristics of persons, events, or situations" (Sakaran \& Bougie, 2013). Metode studi kasus juga turut digunakan dalam penelitian ini. "Studi kasus sebagai metode penelitian yang memiliki tujuan penting dalam meneliti dan mengungkap keunikan serta kekhasan karakteristik yang terdapat dalam kasus yang diteliti, di mana kasus tersebut menjadi penyebab mengapa penelitian dilakukan" (Stake, 2005).

Oleh karena itu, selain menggambarkan fenomena penelitian, penulis juga menggali berbagai macam informasi yang berhubungan dengan kasus yang dibahas dalam penelitian 
ini, baik dari sejarah, kegiatan, laporan tertulis, dan lain sebagainya.

\section{Jenis Data}

Penelitian ini menggunakan data keuangan yang diperoleh dari laporan laba rugi dan neraca yang disajikan dalam runtut waktu (time series) antara tahun 2015-2017. Data sekunder yang diperoleh berupa laporan tahunan dan laporan keuangan perusahaan periode 2015-2017 yang dipublikasikan di website perusahaan yaitu www.tigapilar.com dan juga website resmi Bursa Efek Indonesia yaitu www.idx.co.id.

\section{Teknik Pengumpulan Data}

Pengumpulan data berupa laporan keuangan maupun data pendukung lainnya untuk penelitian ini dilakukan oleh penulis dengan teknik-teknik sebagai berikut: (1) Studi Dokumentasi. Data yang telah didokumentasikan dalam suatu sumber resmi berupa laporan keuangan yang diunduh melalui website resmi Bursa Efek Indonesia (BEI) dan laporan tahunan yang diunduh melalui website resmi perusahaan; (2) Studi Kepustakaan (library research). Pengumpulan data yang dilakukan secara tidak langsung yang relevan dengan masalah yang sedang diteliti dengan cara mempelajari dan menganalisa berbagai macam literatur. Studi kepustakaan yang dilakukan berupa studi literatur dari berbagai buku, jurnal, dan artikel baik dari fisik maupun dunia maya (internet).

Tabel 3. Hasil Perhitungan Altman Z-Score

\begin{tabular}{lllllll}
\multicolumn{7}{l}{ Tabel 3. Hasil Perhitungan Altman Z-Score } \\
\hline Rasio & $\mathbf{2 0 1 7}$ & & $\mathbf{2 0 1 6}$ & & $\mathbf{2 0 1 5}$ & \\
\hline X1 : Modal Kerja / & 634,174 & $\mathbf{0 . 0 7 3}$ & $5,698,731$ & $\mathbf{0 . 6 1 6}$ & $1,713,178$ & $\mathbf{0 . 1 8 9}$ \\
Total Aset & $8,724,734$ & & $9,254,539$ & & $9,060,980$ & \\
\hline X2 : Laba Ditahan / & $1,231,304$ & $\mathbf{0 . 1 4 1}$ & $1,796,408$ & $\mathbf{0 . 1 9 4}$ & $1,215,374$ & $\mathbf{0 . 1 3 4}$ \\
Total Aset & $8,724,734$ & & $9,254,539$ & & $9,060,980$ & \\
\hline X3 : EBIT / Total & $(548,754)$ & $\mathbf{0 . 0 6 3})$ & $1,281,744$ & $\mathbf{0 . 1 3 8}$ & 739,434 & $\mathbf{0 . 0 8 2}$ \\
Aset & $8,724,734$ & & $9,254,539$ & & $9,060,980$ & \\
\hline X4 : Nilai Pasar & 476 & $\mathbf{0 . 0 0 0 1}$ & 1,945 & $\mathbf{0 . 0 0 0 4}$ & 1,210 & $\mathbf{0 . 0 0 0 2}$ \\
Saham / Total Utang & $5,319,855$ & & $4,990,139$ & & $5,094,073$ & \\
\hline X5 : Penjualan / Total & $4,920,632$ & $\mathbf{0 . 5 6 4}$ & $6,545,680$ & $\mathbf{0 . 7 0 7}$ & $6,010,895$ & $\mathbf{0 . 6 6 3}$ \\
Aset & $8,724,734$ & & $9,254,539$ & & $9,060,980$ & \\
\hline Altman Z-Score & & $\mathbf{0 . 6 4 1}$ & & $\mathbf{2 . 1 7 5}$ & & $\mathbf{1 . 3 4 7}$ \\
\hline Sum
\end{tabular}

Sumber: Hasil Pengolahan Data

\section{Teknik Pengolahan Data}

Teknik pengolahan data yang akan digunakan dalam penelitian ini adalah sebagai berikut: (1) Pengumpulan data berupa data laporan keuangan PT Tiga Pilar Sejahtera Food. Tbk (AISA) tahun 20152017 dari website resmi perusahaan www.tigapilar.com; (2) Data laporan keuangan diambil dari neraca dan laba/rugi dan disortir untuk kemudian dimasukkan dalam rumus persamaan Altman Z-Score dan Zmijewski X-Score; (3) Data yang sudah dihitung pada poin 2 kemudian diinterpretasi sesuai dengan hasil dari perhitungan metode prediksi kebangkrutan dengan cut-off nya masing-masing; (4) Setelah didapatkan hasil interpretasi dan analisis masing-masing metode, maka dikomparasikan atau dibandingkan hasil analisis masing-masing, sehingga dapat dilihat apakah metode Altman Z-Score dan Zmijewski X-Score memberikan hasil keputusan yang sama atau tidak, yaitu perusahaan akan bangkrut atau tidak bangkrut (dalam kondisi sehat), atau bisa saja kedua metode menghasilkan hasil yang berbeda.

\section{Hasil dan Pembahasan}

\section{Hasil Perhitungan Altman Z-Score}

Hasil perhitungan rasio-rasio dalam metode prediksi kebangkrutan Altman ZScore beserta angka Z-Score yang diperoleh dapat dilihat pada Tabel 3 .

Berdasarkan Tabel 3, dapat dilihat bahwa dalam 3 (tiga) tahun sejak 2015-2017, kondisi dan keadaan perusahaan cukup jauh 
dari kata sehat. Angka Z-Score yang diperoleh pada tahun 2015 sebesar 1.347 yang masih jauh dibawah cut off yaitu 1.81 . Pada tahun 2016, angka Z-Score berhasil melewati cut off 1.81 dengan perolehan ZScore sebesar 2.175. Namun demikian, angka tersebut masih menunjukkan kondisi keraguraguan (Grey zone) untuk kategori perusahaan sehat, sehingga belum bisa dinyatakan dalam kondisi perusahaan yang sehat dan aman. Dan pada puncaknya tahun 2017, angka Z-Score terjun bebas mencapai angka 0.641 yang sangat jauh dari cut off 1.81 dan tentu dikategorikan dalam perusahaan yang terindikasi mengalami kebangkrutan.

Dengan demikian berdasarkan perhitungan Altman Z-Score, PT Tiga Pilar Sejahtera (AISA) telah terindikasi kebangkrutan (Distress zone) pada periode tahun 2015-2017.

\section{Hasil Perhitungan Zmijewski X-Score}

Hasil perhitungan rasio-rasio dalam metode prediksi kebangkrutan Zmijewski XScore beserta angka X-Score yang diperoleh dapat dilihat pada Tabel 4.
Dengan demikian berdasarkan perhitungan Zmijewski X-Score, PT Tiga Pilar Sejahtera (AISA) dinyatakan dalam kondisi sehat pada periode tahun 2015-2017.

\section{Komparasi Metode Prediksi Kebangkrutan}

Perbandingan atau komparasi hasil perhitungan metode prediksi kebangkrutan Altman Z-score dan Zmijewski X-Score dapat dilihat pada Tabel 5 .

Berdasarkan Tabel 5., dapat dilihat bahwa hasil perhitungan X-Score memiliki hasil yang sangat berbeda dengan perhitungan Z-Score pada. Metode perhitungan X-Score menghasilkan angka negatif selama periode 2015-2017, yang berarti perusahaan tergolong dalam kategori sehat. Sedangkan perhitungan Z-Score menghasilkan angka positif selama periode 2015-2017. Namun angka positif tersebut belum mampu melewati angka cut off 1.81 . Tahun 2016, angka Z-Score memang sudah mampu melewati cut off 1.81 , tetapi masih masuk dalam zona grey zone (abu-abu) yang berarti masih ada keragu-raguan dalam penetapan kondisi sehat perusahaan dan pada akhirnya masih belum bisa dikategorikan

Tabel 4. Hasil Perhitungan Zmijewski X-Score

\begin{tabular}{lrlrrrr}
\hline Rasio & \multicolumn{2}{c}{$\mathbf{2 0 1 7}$} & \multicolumn{2}{c}{$\mathbf{2 0 1 6}$} & \multicolumn{2}{c}{$\mathbf{2 0 1 5}$} \\
\hline X1=EAT / Total & $-846,809$ & $\mathbf{( 0 . 0 9 7 )}$ & 719,228 & $\mathbf{0 . 0 7 8}$ & 373,750 & $\mathbf{0 . 0 4 1}$ \\
Aktiva & $8,724,734$ & & $9,254,539$ & & $9,060,979$ & \\
\hline X2=Total Hutang / & $5,319,855$ & $\mathbf{0 . 6 1 0}$ & $4,990,139$ & $\mathbf{0 . 5 3 9}$ & $5,094,072$ & $\mathbf{0 . 5 6 2}$ \\
Total Aktiva & $8,724,734$ & & $9,254,539$ & & $9,060,979$ & \\
\hline X3=Aktiva Lancar / & $4,536,882$ & $\mathbf{1 . 1 6 2}$ & $5,949,164$ & $\mathbf{2 . 3 7 6}$ & $4,463,635$ & $\mathbf{1 . 6 2 3}$ \\
Hutang Lancar & $3,902,708$ & & $2,504,330$ & & $2,750,456$ & \\
\hline Zmijewski X-Score & & $\mathbf{- 0 . 3 9 2}$ & & $\mathbf{- 1 . 5 8 6}$ & & $\mathbf{- 1 . 2 8 8}$ \\
\hline
\end{tabular}

Sumber: Hasil Pengolahan Data

Berdasarkan Tabel 4, dapat dilihat bahwa dalam 3 (tiga) tahun sejak 2015-2017, kondisi dan keadaan perusahaan tergolong sehat. Angka X-Score pada tahun 2017 mengalami kenaikan drastis dikarenakan pada tahun tersebut perusahaan mengalami kerugian lebih dari $100 \%$ dari tahun sebelumnya, 2016. Dapat dilihat bahwa XScore menghasilkan angka negatif selama periode 2015-2017, yang berarti perusahaan tergolong dalam kategori sehat. dalam kondisi perusahaan yang sehat. Hasil $\mathrm{X}$-Score sangat berkebalikan dengan hasil ZScore yang mengindikasikan perusahaan bangkrut dalam periode 2015-2017.

Penyebab perbedaan hasil interpretasi antara Z-Score dan X-Score dipicu oleh adanya perbedaan komponen-komponen rasio yang digunakan dalam perhitungan masing-masing metode. Sehingga dapat dikatakan bahwa tidak semua metode prediksi kebangkrutan memiliki hasil dan 
arah yang sama. Berdasarkan penelitian yang dilakukan oleh Arum dan Handayani (2018) didapatkan hasil bahwa masing-masing hasil yang $100 \%$ akurat dalam memprediksi kebangkrutan perusahaan.

Tabel 5. Komparasi Hasil Perhitungan Z-Score dan X-Score

\begin{tabular}{lcccc}
\hline & $\mathbf{2 0 1 7}$ & $\mathbf{2 0 1 6}$ & $\mathbf{2 0 1 5}$ & Kategori \\
\hline Altman Z-Score & 0.641 & 2.175 & 1.347 & Bangkrut \\
\hline Zmijewski X-Score & $(0.392)$ & $(1.586)$ & $(1.288)$ & Sehat \\
\hline Sur
\end{tabular}

Sumber: Hasil Pengolahan Data

Metode Altman, Springate, dan Zmijewski memiliki titik cut-off, rasio, dan koefisien yang berbeda. Komponen rasio Zmijewski hanya memfokuskan pada hutang/leverage dan tidak mempertimbangkan komponen lainnya seperti modal kerja, nilai pasar saham ataupun penjualan berbeda dengan Altman ZScore.

Dengan demikian penelitian ini sejalan dengan penelitian yang dilakukan oleh Hariyani \& Sujianto (2017) dan Primasari (2017) bahwa adanya perbedaan hasil dari metode-metode yang digunakan sebagai metode untuk memprediksi kebangkrutan perusahaan.

Metode-metode prediksi kebangkrutan hanya sebagai signaling bagi perusahaan untuk lebih waspada dalam menghadapi situasi terburuk yang mungkin saja dialami oleh perusahaan. Hasil prediksi metodemetode tersebut juga menjadi bahan evaluasi kinerja perusahaan di masa akan datang. Hasil prediksi metode kebangkrutan yang berbeda menunjukkan bahwa tidak semua metode bisa digunakan setara dalam keadaan dan situasi tertentu. Komponen rasio-rasio yang berbeda tidak selalu memiliki hasil yang berbeda. Jika suatu perusahaan memang sudah dalam keadaan tidak sehat dalam berbagai aspek, kemungkinan metodemetode prediksi kebangkrutan bisa menghasilkan hasil yang sama.

Dalam memprediksi kebangkrutan suatu perusahaan, aspek yang dilihat tidak hanya internal perusahaan, tetapi, eksternal perusahaan juga menjadi faktor penentu keadaan, situasi, dan kinerja perusahaan, seperti faktor ekonomi, politik, persaingan, dan lain-lain. Sehingga semua metodemetode prediksi kebangkrutan yang banyak digunakan saat ini tentu belum menghasilkan

\section{Kesimpulan dan Saran}

\section{Kesimpulan}

Berdasarkan penelitian yang telah dilakukan terhadap PT Tiga Pilar Sejahtera (AISA), dapat ditarik kesimpulan bahwa: (1) Perhitungan Altman Z-Score memprediksi bahwa AISA terindikasi kebangkrutan dengan angka yang diperoleh pada periode 2015-2017 menunjukkan angka positif yang kurang dari cut off yang berarti bahwa perusahaan berada dalam kategori kebangkrutan (Distress zone) dan abu-abu (Grey zone); (2) Perhitungan Zmijewski XScore memprediksi bahwa AISA dalam kondisi yang sehat ditunjukkan dengan angka perhitungan periode 2015-2017 adalah negatif dan tidak mencapai angka 0 ; (3) Berdasarkan penelitian ini didapatkan bahwa adanya perbedaan hasil perhitungan antara Altman Z-Score dan Zmijewski X-Score terhadap PT Tiga Pilar Sejahtera pada periode 2015-2017. Angka Z-Score menunjukkan menunjukkan perusahaan terindikasi bangkrut, sedangkan angka $\mathrm{X}$ Score menunjukkan perusahaan dalam keadaan yang sehat; (4) Perbedaan dapat dipicu oleh adanya perbedaan komponenkomponen rasio yang digunakan dalam perhitungan masing-masing metode. Sehingga dapat dikatakan bahwa tidak semua metode prediksi kebangkrutan memiliki hasil dan arah yang sama; (5) Dalam memprediksi kebangkrutan suatu perusahaan, aspek yang dilihat tidak hanya internal perusahaan, tetapi, eksternal perusahaan juga menjadi faktor penentu keadaan, situasi, dan kinerja perusahaan; (6) Metode-metode prediksi kebangkrutan yang banyak digunakan saat ini tentu belum menghasilkan hasil yang 100\% akurat dalam memprediksi kebangkrutan perusahaan. 
Saran

Berdasarkan kesimpulan yang dihasilkan maka saran-saran yang dapat diberikan kepada pihak-pihak yang membutuhkan sebagai berikut: (1) Bagi peneliti selanjutnya, penelitian diharapkan dapat menggunakan periode waktu laporan keuangan yang lebih panjang, misal 5 (lima) tahun. Agar hasil yang didapatkan lebih akurat; (2) Bagi peneliti selanjutnya, penelitian dengan topik yang sama diharapkan dapat menggali lebih dalam mengenai metode-metode prediksi kebangkrutan yang dapat dituangkan dalam penelitian selanjutnya. Misalnya menggunakan lebih dari 2 (dua) metode dalam memprediksi kebangkrutan, agar hasil yang didapatkan lebih banyak sudut pandang yang dibahas dalam penelitian; (3) Bagi perusahaan, penelitian ini hanya sebagai gambaran keadaan perusahaan yang tidak $100 \%$ benar. Hasil perhitungan metodemetode digunakan sebagai evaluasi kedepannya agar perusahaan dapat memperbaiki kinerjanya; (4) Bagi Investor, penelitian ini bisa dijadikan referensi dan tolak ukur untuk mengambil keputusan investasi pada perusahaan agar investor juga mengetahui bagaimana keadaan dan kondisi saat ini maupun yang akan datang.

\section{Daftar Referensi}

Adriana, A. (2012). Analisis Prediksi Kebangkrutan Menggunakan Metode Springate Pada Perusahaan Foods and Beverages yang Terdaftar di Bursa Efek Indonesia Periode 2006-2010. E-Jurnal Repository Akuntansi Universitas Riau, Vol. 4 (1), 5-20.

Altman, E. (1968). Financial Ratio, Discriminant Analysis and The Prediction of Corporate Bankcruptcy. Journal of Finance, Vol. XXIII(No. 4), 589-609.

Arum, D. P., \& Handayani, S. R. (2018, Juli). Analisis Perbandingan Metode Altman (Z-Score), Springate (S-Score), dan Zmijewski (X-Score) Dalam Memprediksi Kebangkrutan Perusahaan (Studi Pada Perusahaan Tekstil dan
Garmen Yang Terdaftar di Bursa Efek Indonesia Periode 2012-2016). Jurnal Administrasi Bisnis (JAB), Vol. 60(No. 1).

businessinsight.kontan.co.id. (2018). Asa Tiga Pilar Sejahtera. Retrieved 2019, from business insight: https://businessinsight.kontan.co.id/new s/asa-tiga-pilar-sejahtera

dataindustri.com. (2017). Data Pertumbuhan Industri Makanan dan Minuman. Retrieved 2019, from data industri research:

https://www.dataindustri.com/produk/da ta-pertumbuhan-industri-makanan-danminuman/

ekonomi.kompas.com. (2017, Desember 20). Hentikan Bisnis Beras, PT Tiga Pilar PHK 1700 Karyawan. Retrieved Mei 2019, from ekonomi kompas: https://ekonomi.kompas.com/read/2017/ 12/20/184700326/hentikan-bisnis-beraspt-tiga-pilar-phk-1.700-karyawan.

ekonomi.kompas.com. (2019, January 11). Mengurai Permasalahan dan Isu Pailit yang dialami Produsen Taro. Retrieved July 2019, from ekonomi kompas: https://ekonomi.kompas.com/read/2019/ 01/11/153635826/menguraipermasalahan-dan-isu-pailit-yangdialami-produsen-taro?page $=$ all.

Fanny, M., \& Saputra, S. (2005, September 15-16). Opini audit going concern: kajian berdasarkan model prediksi kebangkrutan, pertumbuhan perusahan, dan reputasi kantor akuntan publik pada emiten Bursa Efek Jakarta. Simposium Nasional Akuntansi. VIII pg. 966-976. Solo, Jawa Tengah.

Gitman, L., \& Zutter, C. (2012). Principles of Managerial Finance 13th Edition. Edinburg.

Hariyani, D. S., \& Sujianto, A. (2017, Oktober). Analisis Perbandingan Model Altman, Model Springate, Dan Model Zmijewski Dalam Memprediksi 
Kebangkrutan Bank Syariah Di Indonesia. Jurnal Akuntansi, Vol. 1(No. $1)$.

Lin, B., Zu-Hsu, L., \& Gibbs, L. G. (2008). Operational restructuring. In: Management Desicion, 46 (4), 539-552.

neraca.co.id. (2019). Triwulan I 2019 Industri Makanan dan Minuman Topang Pertumbuhan Pengolahan. Retrieved July 2019, from neraca: https://www.neraca.co.id/article/116588/ triwulan-i-2019-industri-makanan-danminuman-topang-pertumbuhanpengolahan

PEFINDO. (2018, Mei 16). Credit Profile : PT Tiga Pilar Sejahtera Food Tbk. Credit Profile. Siaran Pers.

Permana, R. K., Ahmar, N., \& Djaddang, S. (2017, Oktober). Prediksi Financial Distress pada Perusahaan Manufaktur di Bursa Efek Indonesia. Jurnal Bisnis dan Manajemen, Vol. 7 (2)(P-ISSN : 20872038; E-ISSN : 2461-1182), 149-166.

Primasari, N. S. (2017, July). Analisis Altman Z-Score, Grover Score, Springate, dan Zmijewski Sebagai Signaling Financial Distress (Studi Empiris Industri Barang-Barang Konsumsi di Indonesia). Accounting and Management Journal, Vol. 1(No. 1).

Rahayu, \& Putri. (2016). Analisis Penggunaan Metode Springate (S-Score) sebagai Prediktor Kebangkrutan (Studi pada Perusahaan Textile yang Terdaftar di Bursa Efek Indonesia pada Tahun 2011-2013). Jurnal Ekonomi, Vol. 1 (1), 55-68.
Sakaran, U., \& Bougie, R. (2013). Research Methods for Business. United Kingdom: John Wiley \& Sons Ltd.

Stake, R. (2005). The Art of Case Study. London: Sage Publications, Inc.

Sugiyono. (2014). Metode Penelitian Pendidikan Pendekatan Kuantitatif, Kualitatif, dan R\&D. Bandung: Alfabeta.

Sundjaja, R., Barlian, I., \& Sundjaja, D. (2013). Manajemen Keuangan I. Jakarta: Literara Lintas Media.

tigapilar.com. (2019). Financial Statement. Retrieved July 2019, from tigapilar: http://www.tigapilar.com/investor_relati on/financial_statement/tiga_tahun_terak hir

tirto.id. (2018). Di Balik Rontoknya Saham Produsen Beras maknyuss. Retrieved 2019, from tirto id: https://tirto.id/dibalik-rontoknya-saham-produsen-berasmaknyuss-cNb2.

Wulandary, V., \& Nur, E. (2014). Analisis Perbandingan Model Altman, Springate, Ohlson, Fulmer, CA-Score dan Zmijewski Dalam Memprediksi Kesulitan keuangan (studi empiris pada Perusahaan Food and Beverages yang Terdaftar di Bursa Efek Indonesia Periode 2010-2012). JOM FEKOM, Vol. l(No. 2), 1-18.

Zmijewski, M. (1984). Methodological Issues Related to the Estimation of Financial Distress Prediction Models. Journal of Accounting Research, 22, 5982. 
